\title{
Classification of Multi-spectral Landsat Satellite Imagery Dataset using Feature Extraction Methods
}

\section{Saurabh Kumar, Shwetank}

\begin{abstract}
The feature extraction of multi-spectral Landsat satellite imagery Dataset is essential for vegetation monitoring, urban planning, change assessment, and other land-use applications. The spatial information provided by Remote sensing satellite imagery data is helpful for planning and decision-making policies. In the present study, classify the features of the multi-spectral Landsat satellite imagery dataset in different periods using the feature extraction method, and is produced the spatial maps of the study area. The study is to analyze the appropriate method of feature extraction for classifying the orchards, vegetation, rangeland, agricultural land, wetland, water body, and urban land using multi-temporal satellite dataset. In this study, use the three feature extraction methods are support vector machine (SVM), minimum distance (MD), and Maximum likelihood classifier (MLC) for supervised pixel-based classification using medium resolution $(30 \mathrm{~m})$ satellite dataset. The accuracy of feature extraction method is performed by the MLC (86.29\% and 93\% in the year 2003 and 2017) and SVM (86.37\% and $90 \%$ in the year 2003 and 2017). The result of the presented study shows MLC and SVM classifier performs similar results but better than MD classifier for land-use/cover features classification. The classified spatial maps provide the essential spatial information for land-use changes occurred during the last 15 years (2003 to 2017).
\end{abstract}

Keywords: feature extraction, remote sensing, spectral, spatial maps.

\section{INTRODUCTION}

The remote sensing (RS) feature extraction method is to explore the potential of multispectral satellite imagery data and produce the spatial maps. The spatial maps are essential for monitoring and planning of land-use [1] of the study area. The satellite imagery data play a vital role in feature extraction from the earth's surface and provides spatial and temporal information of land cover [2]. The RS shows an essential role in urban sprawl and growth and its impact on vegetation and forest [3].

Revised Manuscript Received on February 28, 2020.

* Correspondence Author

Saurabh Kumar*, Ph.D. Scholar, Department Of Computer Science, Gurukula Kangri Vishwavidyalaya, Haridwar, Uttarakhand, India. Email: rs.saurabhkumar@gkv.ac.in, saurabhpathakkanpur@gmail.com

Shwetank, Assistant Professor, Department Of Computer Science, Gurukula Kangri Vishwavidyalaya, Haridwar, Uttarakhand, India. Email: Shwetank.arya@gmail.com

(C) The Authors. Published by Blue Eyes Intelligence Engineering and Sciences Publication (BEIESP). This is an open access article under the CC-BY-NC-ND license http://creativecommons.org/licenses/by-nc-nd/4.0/
Numerous researchers had applied the multispectral Landsat satellite data to monitoring and observations in local and global for land use applications because USGS freely provides it in digital format and contains a wide range of spectral bands [4-5]. The multispectral Landsat dataset has the potential to mapping, observations, monitoring, and change assessment in various fields of vegetation [6], agriculture [7], forestry [8], and urbanization [9]. The RS techniques are beneficial in environment monitoring [10] and change predictions. The RS and geographical information system (GIS) tools are essential for spatial analysis and change assessment in land use applications (vegetation mapping, crops cultivation monitoring, urban mapping, etc.) The study is to analyze the appropriate supervised classification method for feature extraction from remote sensing satellite images.

\section{STUDY AREA}

The Haridwar region selected as a study area is situated in Uttarakhand state of the south-western position between $29.58^{\circ}$ latitude and $78.13^{\circ}$ longitude. Haridwar is the gate of holy river Ganga and a famous Hindu pilgrimage. The weather of the study region is in summers around $25^{\circ} \mathrm{C}$ to $44^{\circ} \mathrm{C}$ and winters $-2^{\circ} \mathrm{C}$ to $24^{\circ} \mathrm{C}$, yearly regular rainfall 1174.3 $\mathrm{mm}$. Haridwar district has contained three subdivisions (viz. Haridwar, Laksar, and Roorkee), and covered 2,360 km² area It has six administrative blocks and 610 villages, with 18,90 , 422 population according to the 2011 census. Haridwar region is a vital place for horticultural fruits and crop cultivation in Uttarakhand. The QGIS 2.18 (open-source tool) is used to prepare the spatial maps of the study region and show in figure 1.

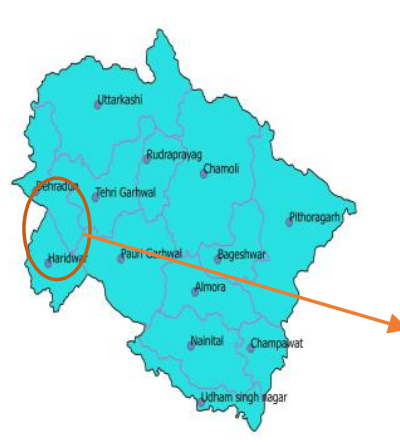

Uttarakhand map

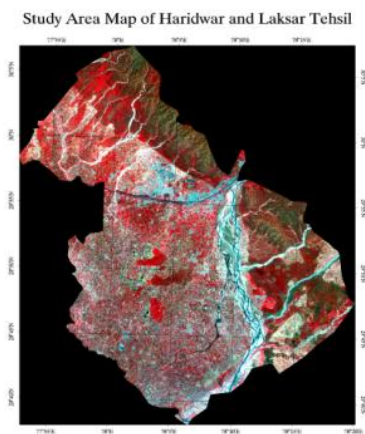

*
Fig. 1. Map of study area

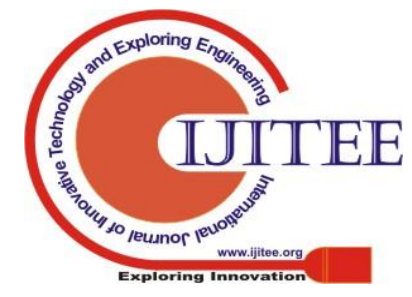




\section{DATASET}

In the proposed study, Landsat-8 OLI and Landsat-7 ETM+ satellite imagery dataset used as primary data, and secondary data are used as reference data for accuracy assessment of classified dataset. The secondary dataset has collected information (in the form of ground control points (GCP)) by ground survey using a hand-held Garmin 60 GPS device. The topographic map of the Haridwar region is essential for accurate assessment of primary data acquired from the survey of India Dehradun at the $1 / 25,000$ scale. The secondary information has led to the approval of the correctness of information despite the whole study depend on the primary dataset. All essential information about the primary dataset has acquired from the United States Geological Survey (USGS) mentioned in table 1 .

Table 1. Detailed of acquired Landsat 8 OLI satellite imagery data used for feature extraction.

\begin{tabular}{|c|c|c|c|c|c|c|}
\hline $\begin{array}{c}\text { Name of } \\
\text { dataset }\end{array}$ & $\begin{array}{l}\text { Source } \\
\text { of data }\end{array}$ & $\begin{array}{c}\text { Acquirement } \\
\text { date }\end{array}$ & $\begin{array}{l}\text { Spatial } \\
\text { resolution }\end{array}$ & Band & $\begin{array}{c}\text { UTM } \\
\text { Zone/ } \\
\text { Datum }\end{array}$ & Wavelength $(\mu \mathrm{m})$ \\
\hline $\begin{array}{l}\text { Landsat-7 } \\
\text { ETM+ }\end{array}$ & USGS & 07/03/2003 & $\begin{array}{l}30 \text { and } 15 \\
\mathrm{~m}(\mathrm{~B} 8)\end{array}$ & $\begin{array}{l}\text { B1-Blue, B2-Green, } \\
\text { B3-Red, B4-NIR, } \\
\text { B5-SWIR, B6-TIR, } \\
\text { B7-SWIR and } \\
\text { B8-PAN }\end{array}$ & $\begin{array}{c}44 / \mathrm{WGS} \\
84\end{array}$ & $\begin{array}{l}\mathrm{B} 1(0.45-0.52), \quad \mathrm{B} 2(0.52-0.60), \\
\mathrm{B} 3(0.63-0.69), \\
\mathrm{B} 5(1.55-1.75), \\
\mathrm{B} 7(2.77-0.90),\end{array}$ \\
\hline $\begin{array}{l}\text { Landsat-8 } \\
\text { OLI }\end{array}$ & USGS & 08/05/2017 & $\begin{array}{c}30 \mathrm{~m} \\
\text { (B1-B7), } 15 \\
\mathrm{~m} \text { (B8)and } \\
100 \mathrm{~m} \\
\text { (B10-B11) }\end{array}$ & $\begin{array}{lr}\text { B1-Coastal } & \text { Aerosol } \\
\text { B2-Blue, B3-Green, } \\
\text { B4-Red, } \\
\text { B6-SWIR, B7-SWIR, } \\
\text { B8-PAN, B9-Cirrus, } \\
\text { B10-TIRS 1 and } \\
\text { B11-TIRS } 2\end{array}$ & $\begin{array}{c}\text { 44/WG } \\
\text { S84 }\end{array}$ & $\begin{array}{l}\mathrm{B} 1(0.43-0.45), \mathrm{B} 2(0.45-0.51), \\
\mathrm{B} 3(0.53-0.59), \mathrm{B} 4(0.63-0.67), \\
\mathrm{B} 5(0.85-0.87), \mathrm{B} 6(1.55-1.65), \\
\mathrm{B} 7(2.10-2.29), \mathrm{B} 8(0.50-0.67), \\
\mathrm{B} 9(1.36-1.38), \\
\mathrm{B} 10(10.60-11.19) \text { and } \\
\mathrm{B} 11(11.50-12.51)\end{array}$ \\
\hline
\end{tabular}

\section{METHODOLOGY}

The proposed methodology for feature extraction is used multi-spectral Landsat-8 OLI dataset as a primary data and ground survey, topographic map, and google earth images as secondary data. The preprocessing of a primary dataset is an essential part of accurate feature extraction and analysis.

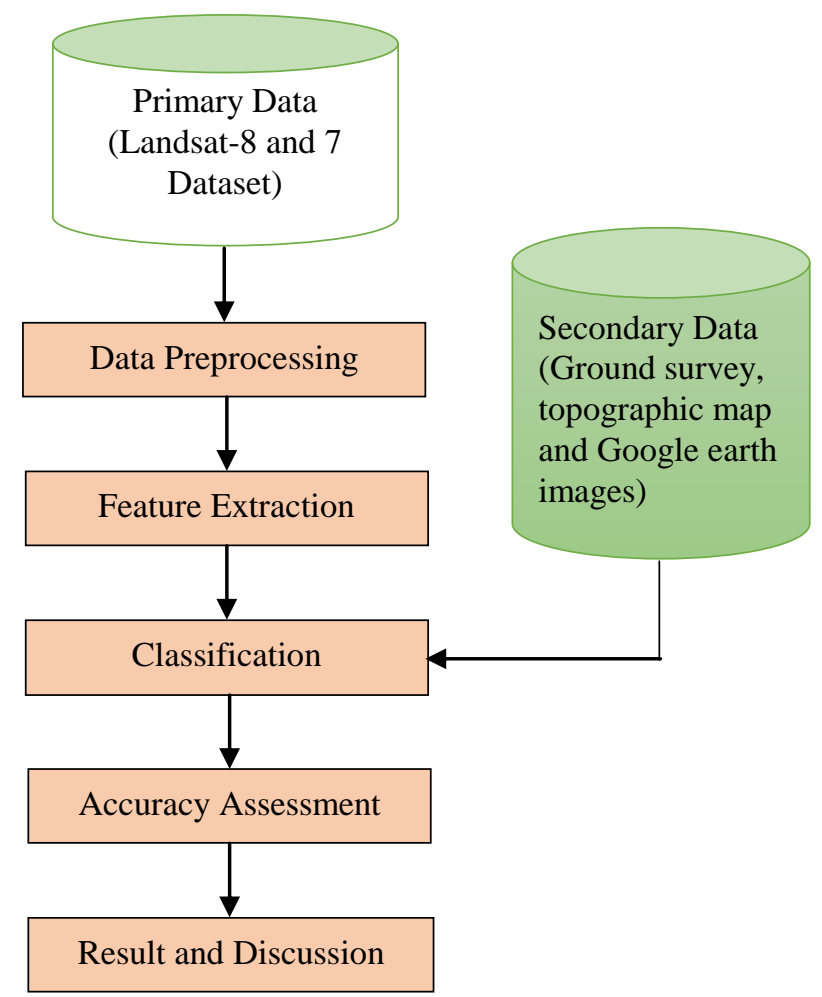

Fig. 2. Methodology for feature extraction.

The satellite images are preprocessed using the Geometric correction and Atmospheric correction method.
The Geometric correction method is used for eliminating the geometric distortion. Since two different periods (2003 and 2017) images are used for feature extraction, so that image registration is essential for the multi-temporal study. The Landsat-8 image (2017) is used as a reference image for registered to another image.

The atmospheric correction method is used to reduce the atmospheric disturbance and recover the surface reflectance from images by removing atmospheric effects. The atmospheric disturbance problems are water vapour and scattering (due to molecules and aerosols), absorption (due to $\mathrm{CO} 2, \mathrm{O} 2, \mathrm{O} 3$ ) effects in the atmosphere. Atmospheric correction is most important when extracting features based on the spectral response of images picked up under different circumstances. The overall process of feature extraction is show in the figure 2 .

\section{A. Feature extraction from multi-spectral Landsat dataset}

The land of the study area is covered various types of land-use, such as orchards, vegetation, open mixed forest, dense mixed forest, agricultural land, rangeland, watershed, water body, and urban. The land cover is distributed into seven classes according to the spectral response of reflected energy with the help of Google earth images and topographic maps. All details of land-use classes are described in table 2. 
Table 2. Details of land cover classes for feature extraction.

\begin{tabular}{|c|c|c|l|}
\hline Sr. No. & Type of classes & Color of classes & \multicolumn{1}{|c|}{ Details of classes } \\
\hline $\mathbf{1 .}$ & Orchards & Green & Various types of horticulture fruit crops mainly mango, litchi, etc. \\
\hline $\mathbf{2 .}$ & Vegetation & Sea Green & Dense mixed forest, Poplar plants, Eucalyptus plants and Hills land. \\
\hline $\mathbf{3 .}$ & Rangeland & Cyan & Woodland, shrub land, open mixed forest, grassland and wetland \\
\hline $\mathbf{4 .}$ & Agricultural land & Yellow & Farmland, crops land (wheat, rice, sugarcane, etc.) and pasture \\
\hline $\mathbf{5 .}$ & Urban land & Red & $\begin{array}{l}\text { Urban-Inhabited, commercial area, rural community, build-up Inhabited } \\
\text { region, Industrial zones and roads }\end{array}$ \\
\hline $\mathbf{6 .}$ & Water body & Blue & River, waterway and pounds \\
\hline $\mathbf{7 .}$ & Watershed & White & Watershed land \\
\hline
\end{tabular}

The total area of land-use classes in the study area is covered 1, 20,136.05 ha. The maximum land cover is covered by agricultural land and minimum land covered by the water body. The orchards are also playing an essential role in food security and the economy of the Haridwar region. The vegetation and rangeland of the Haridwar region contain dense mixed forest, hills plant, open mixed forest, shrubs wetland plants, grasses, etc.

\section{B. Accuracy assessment}

Accuracy assessment measures the accuracy of all applied feature extraction methods individually. In this study, the Post classification method has measured the accuracy of the classifier using the confusion matrix show in table 3 to 8 . The confusion matrix contains spatial information of known and predicted class variables. The Confusion matrix elements (i and j) are no. Samples with predicted class $i$ and known class j. the diagonal elements represent accurately classified observations. Accuracy of classification is depended on various factors such as the resolution of satellite data, preprocessing, data sampling, secondary data, and appropriate selection of feature extraction methods. The ground survey, topographic map, and google earth images play a significant role in accuracy assessment.

\section{RESULT}

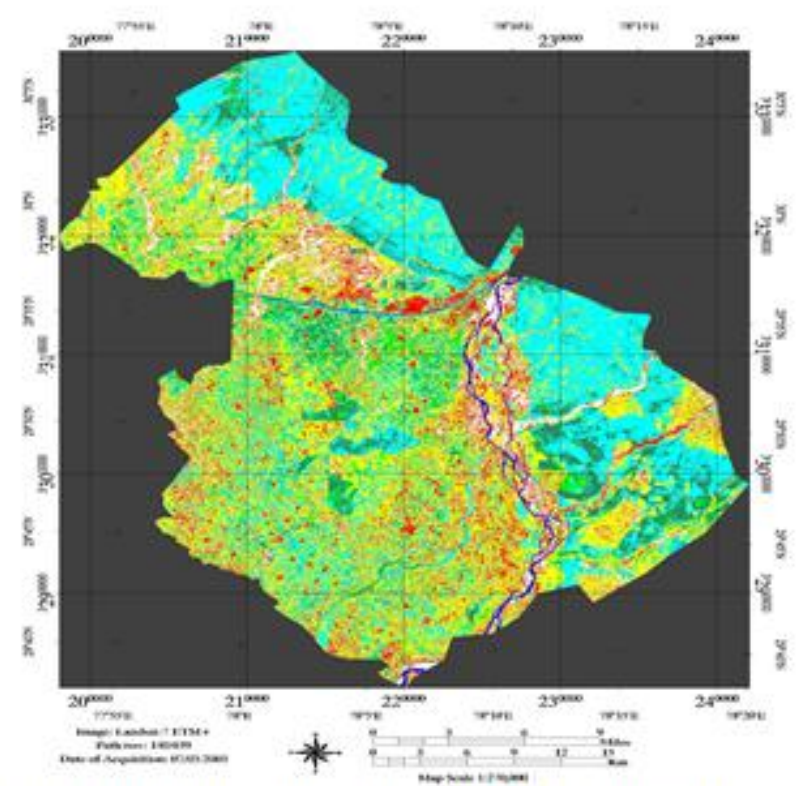

Fig: 3 L andsat-7 (2003) Classified im age using MD

In this study, feature extraction classifier MLC and SVM both are classified with reasonable accuracy to multispectral and mectral Landsat satellite imagery dispe minimum distance method. The classifier classifies the geographic feature such as orchards, vegetation, rangeland, agricultural land, watershed, and water body from multitemporal images (in the year 2003 and 2017) show in classified maps (figure 3 to 8 ).

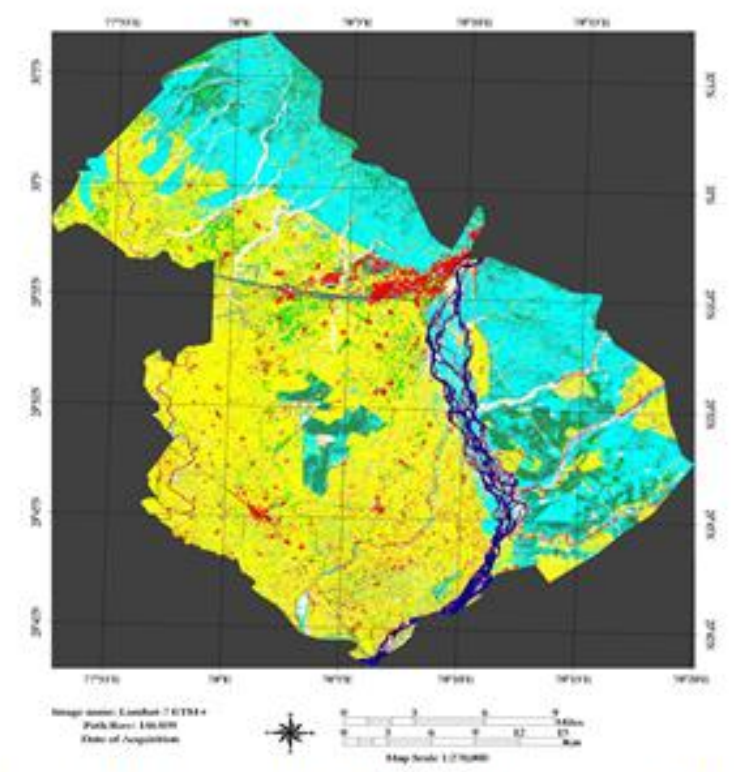

Fig.: 4 Landsat-7 (2003) Classified image using MLC

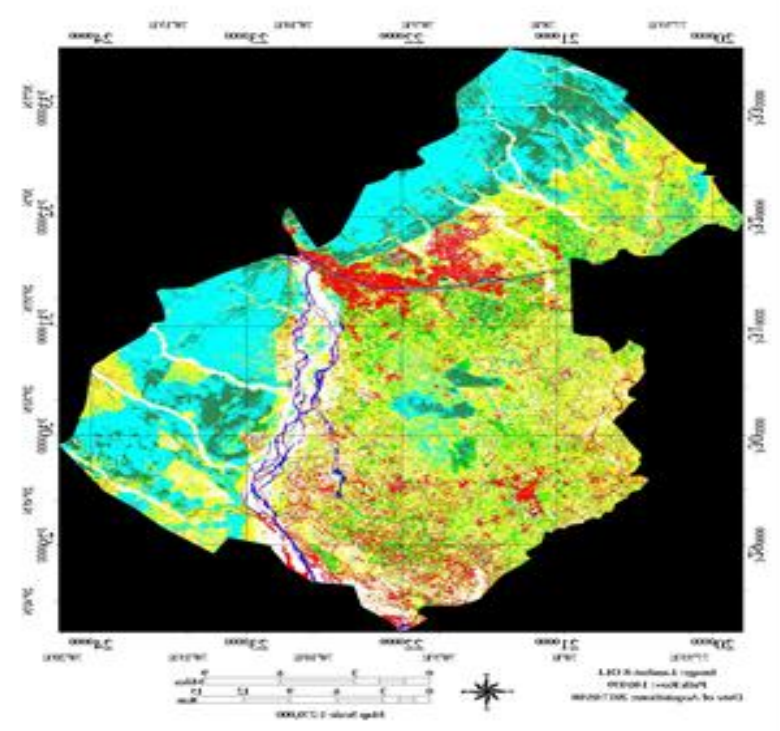

Fig: 5 Landsat-8 (2003) Classified im age using SVM 


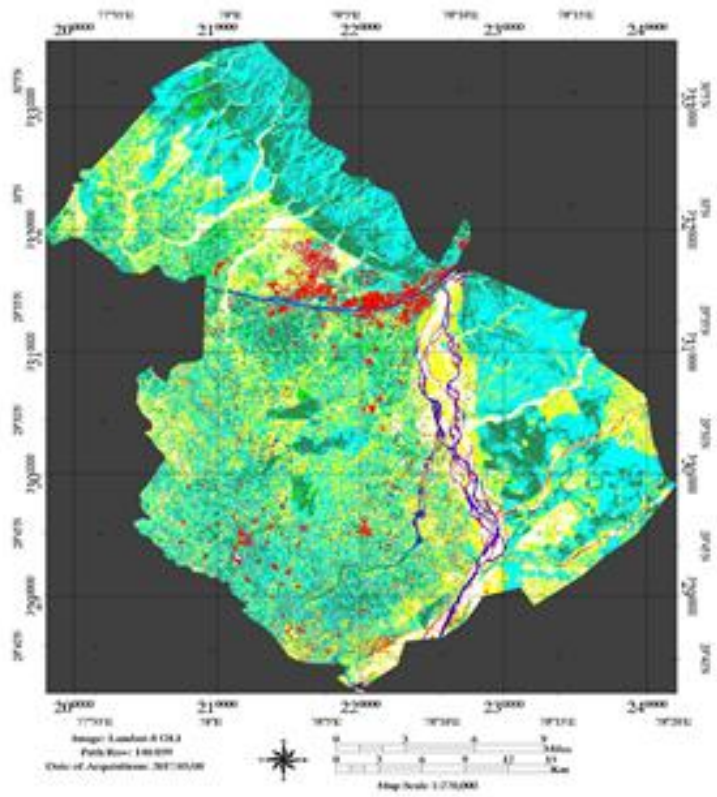

Fig.: 6 L andsat-8 (2017) Classified image using MD

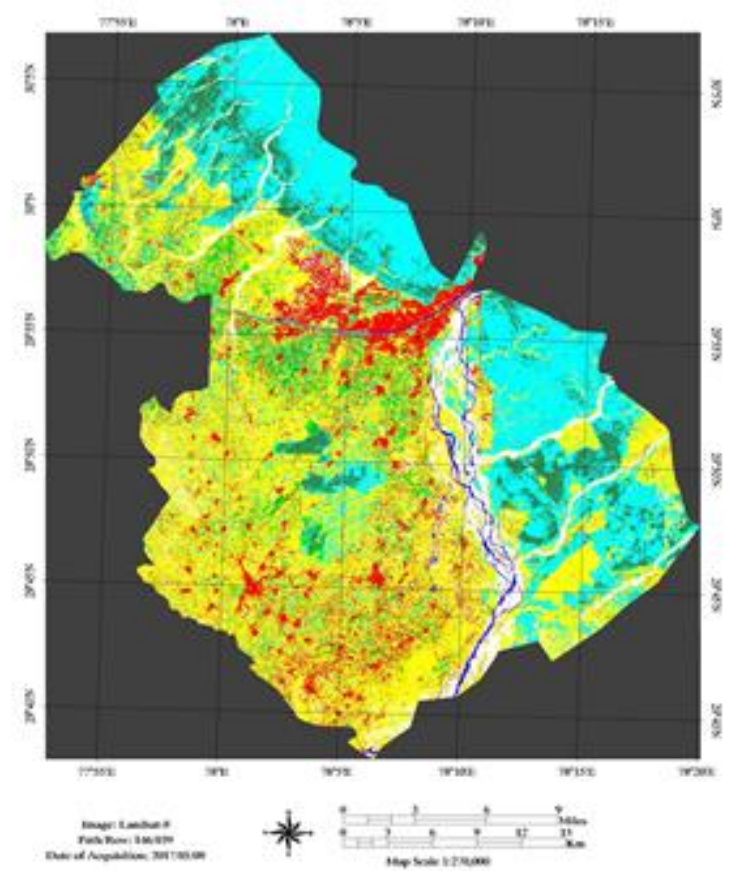

Fig.: 7 L andsat-8 (2017) Classified im age using MLC

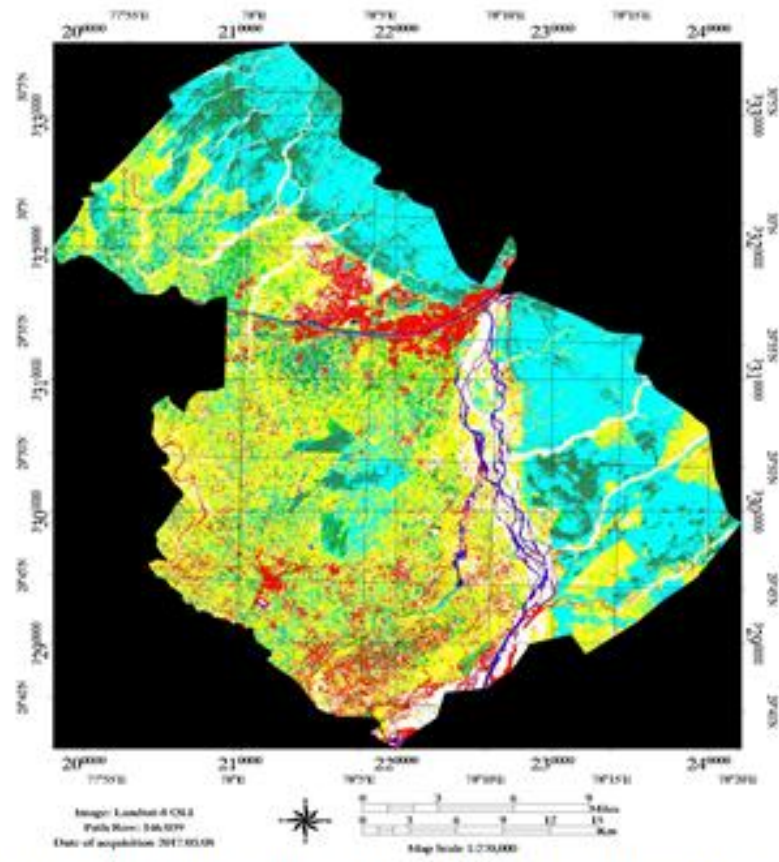

Fig: 8 Landsat-8 (2017) Classified im age using SVM

Each class in the classified spatial map is shown with a unique color. The classified spatial maps are show changes in land use during the last 15 years (2003 to 2017).

MLC and SVM are two standard classifier methods in machine learning. MLC classifier estimates the parameters of the probabilistic model based on Bayesian theory, while SVM, in this case, is based on an optimized nonparametric method. Recently, it was found that in the probabilistic modeling learning process, SVM is equivalent to MLC in some cases.

The accuracy of MLC classifier is $86.29 \%$ and $93 \%$ with kappa $0.83,0.91$ in 2003 and 2017 respectively, and for SVM classifier the accuracy is $86.37 \%$ with kappa $0.83,90 \%$ with kappa 0.87 in 2003 and 2017 respectively and for MD classifier the accuracy is $71.63 \%$ with kappa $0.66,78.56 \%$ with kappa 0.73 in 2003 2017. The accuracy of SVM and MLC classifier in this study shows perform better accurate result than minimum distance classifier for land-use classification and analysis.

Table 3. Confusion matrix of land-use classes classify by the MD in 2003

$$
\text { Kc Value }
$$


Table 4. Confusion matrix of Landuse classes classify by the MLC in 2003.

\begin{tabular}{|c|c|c|c|c|c|c|c|c|}
\hline \multicolumn{8}{|c|}{ Ground Truth Data (\%) } \\
\hline Class & Orchards & Vegetation & $\begin{array}{c}\text { Range } \\
\text { Land }\end{array}$ & $\begin{array}{c}\text { Agri. } \\
\text { land }\end{array}$ & Urban land & Water body & Watershed & Total \\
\hline Orchards & $\mathbf{8 5 . 7 3}$ & 7.46 & 0.63 & 3.75 & 0.12 & 0.00 & 0.10 & $\mathbf{8 . 6 4}$ \\
\hline Vegetation & 11.50 & $\mathbf{9 0 . 3 7}$ & 2.12 & 0.97 & 0.00 & 0.00 & 0.35 & $\mathbf{1 5 . 4 3}$ \\
\hline Rangeland & 0.10 & 1.46 & $\mathbf{8 7 . 8 6}$ & 10.71 & 0.04 & 0.00 & 1.15 & $\mathbf{1 7 . 2 9}$ \\
\hline Agri. Land & 2.18 & 0.71 & 8.17 & $\mathbf{7 6 . 6 9}$ & 5.77 & 0.00 & 9.72 & $\mathbf{1 6 . 6 6}$ \\
\hline Urban land & 0.00 & 0.00 & 0.72 & 3.11 & $\mathbf{9 0 . 5 5}$ & 2.39 & 8.52 & $\mathbf{1 9 . 9 8}$ \\
\hline Water body & 0.00 & 0.00 & 0.00 & 0.24 & 0.00 & $\mathbf{9 6 . 1 7}$ & 0.00 & $\mathbf{7 . 8 6}$ \\
\hline Watershed & 0.00 & 0.00 & 0.50 & 4.53 & 3.52 & 1.44 & $\mathbf{8 6 . 1 7}$ & $\mathbf{1 4 . 1 5}$ \\
\hline Total & $\mathbf{1 0 0}$ & $\mathbf{1 0 0}$ & $\mathbf{1 0 0}$ & $\mathbf{1 0 0}$ & $\mathbf{1 0 0}$ & $\mathbf{1 0 0}$ & $\mathbf{1 0 0}$ & $\mathbf{1 0 0}$ \\
\hline \multicolumn{7}{|c|}{ Overall accuracy } & \multicolumn{7}{|c|}{$\mathbf{8 6 . 2 9 \%}$} \\
\hline
\end{tabular}

Table 5. Confusion matrix of Landuse classes classify by the SVM in 2003.

\begin{tabular}{|c|c|c|c|c|c|c|c|c|}
\hline \multicolumn{9}{|c|}{ Ground Truth Data (\%) } \\
\hline Class & Orchards & Vegetation & $\begin{array}{l}\text { Range } \\
\text { Land }\end{array}$ & $\begin{array}{l}\text { Agri. } \\
\text { land }\end{array}$ & Urban land & Water body & Watershed & Total \\
\hline Orchards & 75.02 & 7.01 & 0.23 & 2.63 & 0.08 & 0.00 & 0.20 & 7.48 \\
\hline Vegetation & 19.82 & 90.22 & 2.93 & 0.97 & 0.00 & 0.00 & 0.20 & 16.18 \\
\hline Rangeland & 0.79 & 2.37 & 89.93 & 10.90 & 0.08 & 0.00 & 1.59 & $\mathbf{1 7 . 9 5}$ \\
\hline Agri. Land & 4.16 & 0.40 & 6.05 & 77.96 & 5.69 & 0.00 & 7.22 & 16.16 \\
\hline Urban land & 0.10 & 0.00 & 0.77 & 4.14 & 91.18 & 1.63 & 9.87 & 20.43 \\
\hline Water body & 0.00 & 0.00 & 0.00 & 0.19 & 0.24 & 97.70 & 0.00 & 8.02 \\
\hline Watershed & 0.10 & 0.00 & 0.09 & 3.21 & 2.73 & 0.67 & 80.92 & 13.78 \\
\hline Total & 100 & 100 & 100 & 100 & 100 & 100 & 100 & 100 \\
\hline \multicolumn{2}{|c|}{ Overall accuracy } & \multicolumn{7}{|c|}{$86.37 \%$} \\
\hline \multicolumn{2}{|c|}{ Kc Value } & \multicolumn{7}{|c|}{0.83} \\
\hline
\end{tabular}

Table 6. Confusion matrix of Landuse classes classify by the MD in 2017.

\begin{tabular}{|c|c|c|c|c|c|c|c|c|}
\hline \multicolumn{9}{|c|}{ Ground Truth Data (\%) } \\
\hline Class & Orchards & Vegetation & $\begin{array}{l}\text { Range } \\
\text { land }\end{array}$ & $\begin{array}{l}\text { Agri. } \\
\text { Land }\end{array}$ & $\begin{array}{c}\text { Urban } \\
\text { land }\end{array}$ & $\begin{array}{l}\text { Water } \\
\text { body }\end{array}$ & Watershed & Total \\
\hline Orchards & 85.44 & 4.91 & 1.23 & 0.14 & 0.00 & 0.00 & 0.00 & 6.70 \\
\hline Vegetation & 14.56 & 89.88 & 15.43 & 1.66 & 0.17 & 0.00 & 0.05 & 26.22 \\
\hline Rangeland & 0.00 & 5.20 & 66.70 & 22.96 & 16.02 & 0.00 & 0.16 & 16.33 \\
\hline Agri. Land & 0.00 & 0.00 & 16.56 & 56.71 & 4.89 & 0.00 & 9.24 & 11.67 \\
\hline Urban land & 0.00 & 0.00 & 0.00 & 0.69 & 78.41 & 0.72 & 12.70 & 10.32 \\
\hline Water body & 0.00 & 0.00 & 0.09 & 0.00 & 0.00 & 99.28 & 0.05 & $\mathbf{6 . 0 7}$ \\
\hline Watershed & 0.00 & 0.00 & 0.00 & 17.84 & 0.51 & 0.00 & 77.79 & 22.68 \\
\hline Total & 100 & 100 & 100 & 100 & 100 & 100 & 100 & 100 \\
\hline Overall accuracy & \multicolumn{8}{|c|}{$\mathbf{7 8 . 5 6 \%}$} \\
\hline Kc Value & \multicolumn{8}{|c|}{0.73} \\
\hline
\end{tabular}

Table 7. Confusion matrix of Landuse classes classify by the MLC in 2017.

\begin{tabular}{|c|c|c|c|c|c|c|c|c|}
\hline \multicolumn{9}{|c|}{ Ground Truth Data (\%) } \\
\hline Class & Orchards & Vegetation & $\begin{array}{c}\text { Range } \\
\text { land }\end{array}$ & $\begin{array}{c}\text { Agri. } \\
\text { Land }\end{array}$ & $\begin{array}{c}\text { Urban } \\
\text { land }\end{array}$ & $\begin{array}{c}\text { Water } \\
\text { body }\end{array}$ & Watershed & Total \\
\hline Orchards & $\mathbf{9 8 . 5 7}$ & 2.57 & 0.00 & 0.14 & 0.00 & 0.00 & 0.00 & $\mathbf{6 . 7 2}$ \\
\hline Vegetation & 0.72 & $\mathbf{9 3 . 3 9}$ & 1.23 & 0.00 & 0.00 & 0.00 & 0.00 & $\mathbf{2 3 . 6 7}$ \\
\hline Rangeland & 0.24 & 3.98 & $\mathbf{9 3 . 4 3}$ & 6.36 & 0.17 & 0.00 & 0.00 & $\mathbf{1 7 . 3 3}$ \\
\hline Agri. Land & 0.24 & 0.06 & 4.91 & $\mathbf{8 8 . 2 4}$ & 4.89 & 0.00 & 6.17 & $\mathbf{1 2 . 3 0}$ \\
\hline Urban land & 0.24 & 0.00 & 0.00 & 2.07 & $\mathbf{9 3 . 5 9}$ & 0.00 & 2.25 & $\mathbf{8 . 9 7}$ \\
\hline Water body & 0.00 & 0.00 & 0.00 & 0.00 & 0.00 & $\mathbf{9 8 . 8 0}$ & 0.00 & $\mathbf{6 . 0 1}$ \\
\hline Watershed & 0.00 & 0.00 & 0.44 & 3.18 & 1.35 & 1.20 & $\mathbf{9 1 . 4 8}$ & $\mathbf{2 5 . 0 0}$ \\
\hline Total & $\mathbf{1 0 0}$ & $\mathbf{1 0 0}$ & $\mathbf{1 0 0}$ & $\mathbf{1 0 0}$ & $\mathbf{1 0 0}$ & $\mathbf{1 0 0}$ & $\mathbf{1 0 0}$ & $\mathbf{1 0 0}$ \\
\hline Overall accuracy & \multicolumn{7}{|c|}{$\mathbf{9 3 . 0 0}$} \\
\hline
\end{tabular}


Table 8. Confusion matrix of Landuse classes classify by the SVM in 2017.

\begin{tabular}{|c|c|c|c|c|c|c|c|c|}
\hline \multicolumn{10}{|c|}{ Ground Truth Data (\%) } \\
\hline Class & Orchards & Vegetation & Rangeland & $\begin{array}{c}\text { Agri. } \\
\text { Land }\end{array}$ & Urban land & $\begin{array}{c}\text { Water } \\
\text { body }\end{array}$ & Watershed & Total \\
\hline Orchards & $\mathbf{8 9 . 0 2}$ & 0.94 & 0.88 & 0.28 & 0.00 & 0.00 & 0.00 & $\mathbf{5 . 8 8}$ \\
\hline Vegetation & 10.50 & $\mathbf{9 5 . 1 5}$ & 6.22 & 0.28 & 0.00 & 0.00 & 0.00 & $\mathbf{2 5 . 5 7}$ \\
\hline Rangeland & 0.00 & 3.92 & $\mathbf{8 6 . 3 3}$ & 13.14 & 0.17 & 0.00 & 0.00 & $\mathbf{1 6 . 8 3}$ \\
\hline Agri. land & 0.48 & 0.00 & 6.57 & $\mathbf{7 6 . 0 7}$ & 6.75 & 0.00 & 4.67 & $\mathbf{1 1 . 0 3}$ \\
\hline Urban land & 0.00 & 0.00 & 0.00 & 0.14 & $\mathbf{8 6 . 6 8}$ & 0.48 & 3.13 & $\mathbf{8 . 4 2}$ \\
\hline Water body & 0.00 & 0.00 & 0.00 & 0.00 & 0.00 & $\mathbf{9 9 . 5 2}$ & 0.05 & $\mathbf{6 . 0 7}$ \\
\hline Watershed & 0.00 & 0.00 & 0.00 & 10.10 & 6.41 & 0.00 & $\mathbf{9 2 . 1 4}$ & $\mathbf{2 6 . 2 0}$ \\
\hline Total & $\mathbf{1 0 0}$ & $\mathbf{1 0 0}$ & $\mathbf{1 0 0}$ & $\mathbf{1 0 0}$ & $\mathbf{1 0 0}$ & $\mathbf{1 0 0}$ & $\mathbf{1 0 0}$ & $\mathbf{1 0 0}$ \\
\hline Overall accuracy & \multicolumn{7}{|c|}{$\mathbf{9 0 . 0 0 \%}$} & \\
\hline
\end{tabular}

\section{CONCLUSION}

In the present study, the RS feature extraction method is explored the geographic feature from the multispectral Landsat 8 OLI and Landsat-7 ETM satellite dataset in the form of spatial maps. The spatial maps are provided the essential spatial information for vegetation mapping, crop monitoring, and urban mapping and planning. The MLC and SVM Classifier classifies the land-use features from the multi-temporal images (in the year 2003 and 2017). The result of this study shows the accuracy of MLC $(86.29 \%$ and $93 \%$ in the year 2003 and 2017 ) and SVM $(86.37 \%$ and $90 \%$ in the year 2003 and 2017) classifier perform better accurate result than minimum distance classifier $(71.63 \%$ and $78.56 \%$ in the year 2003 and 2017) for the land-use classification and change assessment.

\section{ACKNOWLEDGMENT}

The authors of this study are extremely thankful to Professor Kamal Jain, department of civil engineering IIT Roorkee for the help and providing lab for research work.

\section{REFERENCES}

1. Gao Yan, J. -F. Mas , B. H. P. Maathuis, Zhang Xiangmin \& P. M. Van Dijk, "Comparison of pixel-based and object-oriented image classification approaches - a case study in a coal fire area, Wuda, Inner Mongolia, China", International Journal of Remote Sensing, vol. 27, no. 18, pp. 4039-4055, 2007.

2. Peng Gong, et al., "Finer resolution observation and monitoring of global land cover: first mapping results with Landsat TM and ETM+ data", International Journal of Remote Sensing, vol. 34, no.7, pp. 2607-2654, 2013.

3. J.S. Rawat, Manish Kumar, "Monitoring land use/cover change using RS and GIS techniques: A case study of Hawalbagh block, district Almora, Uttarakhand, India" The Egyptian Journal of RS and Space Sciences, no. 18, pp. 77-84, 2015.

4. Jingxiao Zhang, Li Jia, Massimo Menenti and Guangcheng, "Glacier Facies Mapping Using a Machine-Learning Algorithm: The Parlung Zangbo Basin Case Study”, Remote Sensing, vol. 11:452, 2019.

5. Can Bulent Karakus, Orhan Cerit and Kaan Sevki Kavak, "Determination of land use/ cover changes and land use potentials of Sivas city and its surroundings using GIS and RS", Procedia Earth and Planetary Science, vol. 15, pp. 454-461, 2015.

6. DU Peijun, LI Xingli, CAO Wen, LUO Yan, ZHANG Huapeng, "Monitoring urban land cover and vegetation change by multi-temporal RS information", Mining Science and Technology, vol. 20, pp. 0922-0932, 2010.
7. Waldner F., De Abelleyra D., Verón S.R., Zhang M., Wu B., Plotnikov D., Bartalev S., Lavreniuk M., Skakun S., Kussul N., et al., "Towards a set of agrosystem-specific cropland mapping methods to address the global cropland diversity", International Journal of Remote Sensing, vol. 37, no. 14, pp. 3196-3231, 2016.

8. C. Sudhakar Reddy, C. S. Jha, P. G. Diwakar \& V. K. Dadhwal, "Nationwide classification of forest types of India using RS and GIS", Environ Monit Assess Environ, vol. 187, no. 12: 777, 2015.

9. Rajesh Bahadur Thapa and Yuji Murayama, "Examining Spatiotemporal Urbanization Patterns in Kathmandu Valley, Nepal: Remote Sensing and Spatial Metrics Approaches", Remote Sensing, vol. 1, pp. 534-556, 2009.

10. Azzari G., Jain M., Lobell D.B., "Towards fine resolution global maps of crop yields: Testing multiple methods and satellites in three countries", Remote Sensing Environment, vol. 202, pp. 129-141, 2017.

\section{AUTHORS PROFILE}

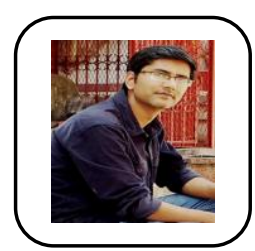

Saurabh Kumar, Ph.D. scholar, department of computer science, Gurukula Kangri Vishwavidyalaya, Haridwar. The area of interest in Remote sensing, GIS and Digital image processing.

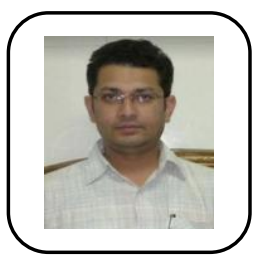

Dr. Shwetank, assistant professor, department of computer science, Gurukula Kangri Vishwavidyalaya, Haridwar. The area of interest in Remote sensing, GIS, Digital image processing and Data mining. He has 15 year experience in teaching and research, and published many research paper in the field of Digital image processing and Remote sensing. 